\title{
FRONTLINE
}

\section{Gentle sounds, distant roar A watershed year for journalism as research}

\begin{abstract}
The Australian and New Zealand Standard Research Classification (ANZSRC) 2020 decision on disciplinary categories has profound implications for journalism as a research discipline. Journalism Practice and Professional Writing retain their six digit Field of Research (FoR) code within the Creative Arts and Writing Division, a new six digit FoR of Journalism Studies has been created in the Division of Language, Communication and Culture, and three new FoR codes of Literature, Journalism and Professional Writing have been created for Aboriginal and Torres Strait Islander, Māori and Pacific Peoples within the new Indigenous Studies Division. This categorisation confirms Journalism as a sovereign and independent discipline distinct from Communication and Media Studies, which has been in bitter contention for more than two decades. The ANZSRC confirmed its 2008 policy that the sole and definitive criterion for categorisation was methodology. This article explores the welcome ramifications of this decision for Journalism within Australasian university-based journalism and charts some of the issues ahead for journalism academics as they embark on the long overdue and fraught path to disciplinary self-recognition as an equal among the humanities and social sciences.
\end{abstract}

Keywords: ANZSRC, Australia, Australian Research Council, communication, field of research, FoR codes, Frontline, journalism practice, journalism research, media studies, New Zealand, PBRF, research disciplines

\section{CHRIS NASH}

Independent Researcher, Sydney

F OR Journalism as a field of research within the Australian and New Zealand academy, 2020 was a watershed year, with forceful implications for teaching and research in the discipline. In July the Australian and New Zealand governments published the conclusions of their 2019-2020 review of the Australian and New Zealand Standard Research Classification (ANZSRC) (ABS et al., 2020). It was conducted on their behalf jointly by the Australian Bureau of Statistics (ABS), the Australian Research Council (ARC), Stats NZ/ Tatauranga Aotearoa and the New Zealand Ministry of Business, Innovation and Employment (MBIE). It confirmed the continuing status of methodology as 
the sole criterion for the definition and categorisation of disciplines. We might expect that the new classification will be in force for a decade or more since the previous version was operative from 2008. It poses considerable opportunities and challenges for Journalism.

There are 23 broad disciplines recognised by the 2020 ANZSRC, within each of which there are three hierarchical levels of Division (with a two digit identifier), Groups (four digits) and Fields (six digits).

Each Division is based on a broad discipline. Groups within each Division are those which share the same broad methodology, techniques and/ or perspective as others in the Division. Each Group is a collection of related Fields. (ABS et al., 2020, p. 7)

The headline outcomes for Journalism were:

1. Journalism Practice, i.e. journalism as a research practice, retained its 2008 location allied with Professional Writing in the Division of Creative Arts and Writing.

2. A field of Journalism Studies has been created under Communication and Media Studies within the Division of Language, Communication and Culture.

3. Three new fields of journalism (allied with literature and professional writing in each instance) were created within the new Division of Indigenous Studies, for Aboriginal and Torres Strait Islander, Māori and Pacific Peoples Studies respectively.

There was some informal discussion when the new classification was first announced that the split between Journalism Practice in the new 3603 Group (formerly the 1903 Group) and Journalism Studies in the new 4701 Group (formerly 2001) had resulted in the separation of practice and theory in journalism. This suggestion is founded on a proposition that journalism practice uses atheoretical craft-based methods and is dependent on Communication Studies for theorisation and analysis. This particular perspective has a history dating back over 20 years in the Australian context, to shortly after the 1993 classification was published. It was pushed strongly by some communication and cultural studies scholars and some journalism educators in the so-called 'Media Wars' of the mid-to-late 1990s (see Hartley, 1996; Bacon, 1997; Windschuttle, Breen \& Bacon, 1998 for an introduction) and ever since. It reveals a fundamental misunderstanding of the ANZSRC system, not to mention the methodological basis of journalism.

The ANZSRC does not recognise craft activity as constituting a field of research. The sole criterion for allocation of a Field of Research (FoR) code is methodology: 'FoR is a classification for research activity according to the 
methodology used in the research' (ABS et al., 2020, p. 5, emphasis in original). A research activity does not get assigned a FoR code without recognition of its own distinctive methodological capacity for productive research and reflexive analysis. Journalism Practice academic researchers are expected to be able to expound, explore and defend the methodological aspects of their practice in ways that are specific to Journalism. They cannot delegate their theoretical responsibilities to other disciplines, and most especially not to disciplines that are based in other Divisions, e.g. Communications. They should be able to identify and explore their commonalities and differences with the other disciplines in their own Group and Division, which for Journalism includes the visual and performing arts, creative and professional writing, screen and digital media and indeed music, in theory and practice. Heady stuff, and light years away from atheoretical, craft-based activity.

Further, the classification categories have been designed according to the principle of Mutual Exclusivity:

Classification categories should be unambiguous, with each unit of research fitting into one category of each component of the classification, without categories overlapping each other. Despite the level of significant change to ANZSRC 2020, extensive efforts have been made to ensure the classification upholds the rule of mutual exclusivity. (ABS et al., 2020, p. 7)

In other words, research practice in Journalism and in Communication and Media Studies are broadly mutually exclusive in the eyes of the ANZSRC, and therefore in the eyes of the ARC, the ERA and New Zealand's MBIE and Performance-Based Research Fund (PBRF). Journalism as a research practice (FoR 360203) is definitively not a subset of Language, Communication and Culture (47). Certainly, Communications Studies can conduct research about Journalism - that is the raison d'etre of the new 470105 FoR - just as journalism can conduct research about communications and cultural industries, products and practices, but each will do so according to their distinctive methodological imperatives, and they are certainly not to be confused with each other.

The same principle of mutual exclusivity applies to the inclusion of journalism within the new Division of Indigenous Studies, which effectively is a proposition that Indigenous journalism practice is methodologically different from non-Indigenous journalism practice. That is a proposition with profound and far-reaching implications for the self-image of classic liberal journalism and its core concept of selfless objectivity. It is also worth noting that just because Journalism Studies is so prominent within Language Communication and Culture (47) that it merits its own six digit code does not mean that journalism as a research object can't be studied by other disciplines, for example History (43), Human Society (44) and Education (39), not to mention Creative Arts and 
Writing (36) and Indigenous Studies (45) where journalism practice is specifically nominated.

The 2020 review was the fourth in a series dating from 1993, four years after the 1989 Dawkins reforms to higher education in Australia removed the binary distinction between research and non-research higher education institutions. The post-Dawkins unified system brought journalism, taught largely in the previously non-research sector of Institutes of Technology and Colleges of Advanced Education, into a world where research was a core requirement and not just a desirable add-on to the core task of teaching. The 1993 classification was conducted by the Australian Bureau of Statistics. It was explicitly aligned with OECD precedents and was a taxonomic recognition of existing patterns of institutional organisation: 'The classification is based primarily on recognised academic disciplines and evolving areas of study' (ABS ASRC, 1993, p. 2).

In the Division of Humanities and Social Sciences, the Subdivision of Media and Communication Studies included 11401 Media Studies, 11402 Journalism and 11403 Library and Information Studies. 120400 Arts, comprising Music, Fine Arts and Drama, was a separate Subdivision, as was 120100 Language and Literature. Five year later, a new classification was issued by the ABS. Again, it followed OECD precedents and recognised existing institutional structures, but added a further specification that it was 'the nature of the R\&D' that was being examined (ABS ASRC, 1998, p. 2, emphasis in original), without specifying how 'nature' was to be identified. Journalism, Librarianship and Curatorial Studies were grouped together in the 400000 Division, the Arts in 410000 and Language and Culture in 420000. Within 400000, Journalism, Technical Writing and Professional Creative Writing were each given their own six digit numbers alongside Communication and Media Studies.

In 2008, Statistics New Zealand Tatauranga Aotearoa combined with the ABS to issue the ANZSRC. Again, it was designed to facilitate national and international comparability. In a move to "to improve and strengthen the conceptual basis and framework that existed with ASRC 1998 .... by rigorously applying a uniform concept across the classification', the undefined term 'nature' was replaced by methodology (ABS ANZSRC, 2008, pp. 2-3, italics in original). As a consequence, Journalism was split off from Communication and Media Studies, and became the four digit 1903 Group Journalism and Professional Writing within the two digit 19 Division of Studies in Creative Arts and Writing. Communication and Media Studies joined with Language and Culture to become the new 20 Division of Language, Communication and Culture.

A couple of points are worthy of note about the 2020 ANZSRC classification in light of this brief historical overview. Firstly, having emerged in 2008, methodology remains unchallenged as the sole criterion for classification and it is very difficult to see that changing in the future: what is more fundamental 
to the nature and quality of research than methodology? Secondly, over four reviews across 27 years, Journalism as a research practice has retreated from being part of the headline nomenclature at the two digit Division level to sharing a six digit Field with Professional Writing. It flags a scathing assessment of the field's performance in developing a research culture and outputs since the 1989 accession to research university status of the institutions wherein it has predominantly been offered.

The failure of Journalism to recognise itself as an independent and sovereign field of academic research practice has its own complex history. Firstly, Australia and New Zealand are not alone, for a start. The UK and Europe, and many countries that follow them, largely persist in a binary classification of research and non-research institutions and consign journalism to non-research status. The actual teachers of journalism are often casual or contract practitioner staff who are excluded from assessments of research performance. In the US, while Columbia University, UC Berkeley and some State Universities have strong reputations in journalism education and production, the Jeffersonian anti-elitist traditions in their national Constitution and history of the press have militated against any claims for academic expertise or 'ivory tower' knowledge that might limit popular access. That said, it is in the US that universities have worked together most effectively with independent funding bodies and non-government organisations to foster high quality investigative research by journalists (Birnbauer, 2019). In the Australian situation, it could be said that the 1989 Dawkins reforms offered journalism academics an unprecedented opportunity to assume international leadership in developing this field at the university level. To date, that opportunity has largely not been recognised or taken up, with isolated individual exceptions.

Secondly, since the late 1990s up until the present, Australian Communications scholars, with a chorus of support from UK colleagues, have assertively argued that journalism is a subset of communications scholarship, and have waged a strong campaign within and across universities to have such subservient status entrenched in departmental structures, curricula, research degree programmes and research grant categories. That conflict first entered the Australian research literature with the Media Wars in the 1990s: the false binary terms of scholarly vs craft definitions were constituted ab initio, which was precisely what needed to be challenged (Bacon 2006). I have been a protagonist in that conflict, and have not the slightest desire to revisit it, firstly because the referee has blown the whistle in ANZSRC 2020 and so the fight is over; and secondly, because to ignore the referee and continue a faux conflict can only be a destructive distraction from the challenge that confronts journalists in the Australasian academy.

In the silence among journalism and communication academics since the decision was announced we can hear the gentle sound of dust settling on old conflicts, and the distant roar of looming turbulence on the Oceania horizon. 
Future scholars in the archaeology of the discipline will find relics of the conflict in the pages of this journal, Australian Journalism Review, the submissions to the 2020 ANZSRC Review and What is Journalism? The Art and Politics of a Rupture (Nash, 2016). In the meantime, the ARC and the PBRF are waiting, perhaps less than patiently, for academic journalists to recognise their place and standing in the research field and get on with the job.

In what remains of this article I want to briefly discuss a few issues to be confronted on the road ahead. Firstly, the definitive issue is methodology. Journalists are no stranger to questions of method. The objective of journalistic inquiry is to make and publish truth claims about some aspect of the world at a given place and time. The claims are generally meant to be verifiable, and able to withstand interrogation and scrutiny. This automatically means that the methods used to discover information and verify the truth claims are also open to interrogation and scrutiny - how do we know what we claim to know? - which in turn necessarily involves questions of methodology: how adequate to the task of establishing and then defending the truth claims were the methods used to gather and analyse the evidence?

So right from the very initiation of a journalistic inquiry, methodological issues arise. The answer to 'what is the story?' is the answer to 'what is the research question?' The standard what, where, when, who, how and why questions of journalistic inquiry immediately demand a set of methods to get answers. Good journalists are extremely practised at discussing and defending their methods whether it be to the chief-of-staff to whom they are pitching their story, their critics and opponents in post-publication controversy, and occasionally in a court of law in defamation proceedings. Gaye Tuchman laid all this out in Making News over 40 years ago and she was one of the very first to label journalism as a 'theoretic activity' (Tuchman, 1978, p. 82, 204). Methodology requires the elaboration and justification of the reasons why the methods used were appropriate to the task of answering the research question. Or put more prosaically: how do you know what you claim to know? And why are those methods adequate to the task?

Journalism does not need to reinvent the wheel on the question of theorising methodology. A lot of other disciplines have been there before us. 'What' requires an empirical method (typically the standard social research methods of observation, witness testimony, document discovery and examination, interview, etc; though also increasingly quantitative methods in data analysis). 'Where' is a question of spatiality, and therefore invokes geography. 'When' is a matter of temporality, and therefore invokes history. 'Who' is a matter of sociology and sometimes psychology. 'How' and 'why' were described by James Carey as 'the dark continent of American journalism' (Carey, 1997): they go straight to the heart of interpretation by the audience, and are usually contested and obscured in political struggle over the production of meaning. Necessarily 'how' and 'why' 
involve interdisciplinarity: one cannot explain an event in political reporting without understanding politics, and the same goes for sports, arts, economics, war and all other genres of reporting. I have discussed these matters in detail elsewhere (Nash 2013, 2014, 2016, 2017).

Secondly, it is essential that journalism teaching move beyond coursework at undergraduate and postgraduate level to embrace postgraduate research degrees specific to their own discipline and not as a subset of other disciplines. This is not a repudiation of interdisciplinarity, but an assertion of responsibility and sovereignty for the discipline with which we have been entrusted by the ANZSRC. I suggest that journalism academic researchers will move ahead in leaps and bounds on the issues in journalism methodology once they start addressing the question with research students (Nash, 2014). Interdisciplinarity will be an excellent venue for identifying the confluences and conflicts in methodology with other disciplines and exploring the specific characteristics, challenges and contribution of journalism.

Thirdly, in their own institutional contexts and at the national level of the ARC and PBRF, journalism academics are going to have to reach out to colleagues in the 36 Division of Creative Arts and Writing. That Division is where decisions on research funding for Journalism will be made, and also the periodic evaluations of quality in research outputs will be made. Journalists will have to make sure that within their own institutions they have representation on the appropriate bodies, and not go cap in hand to other disciplines as currently, to seek to justify themselves in foreign terms. The politics of this at the ARC and PBRF levels should not be so difficult; after all, those bodies have been waiting since 2008 for Journalism to recognise itself; they will probably sigh with relief.

Within individual institutions, it will be a very different story because money and power are involved. It is quite possible that the older established research institutions will turn away from journalism research practice, because for them historically journalism was always an addendum to a pre-existing communications studies programme, and the competitive research strength lies with the latter. At the newer universities, or where journalism has a strong educational history, the balance and comparative advantage will vary. At all universities, in the current climate of dependence on outside commercial organisations for collaborative research funding and with governments often hostile to critical journalism, there will be apprehension at senior levels about what threat independent journalism might pose to corporate well-being. Either way, it will be essential for journalists seeking research grants to approach their own disciplinary bodies, to make sure they have their own representatives on those bodies, to engage independently with the funding and quality evaluation processes, and to organise collectively to defend their common professional interests and academic integrity.

Fourthly, all of the above and particularly the need for interdisciplinary 
understanding will precipitate a need for curriculum review and change away from the current Communications dependent mode. This again will be hardfought because of the funding implications for disciplines, and because many senior Journalism academics have dual appointments in Journalism and Communications. As a process it will probably need to follow rather than precede steps addressing the research profile, and therefore does not need further discussion in this article. There is already and extensive literature on this topic internationally (see Bacon, 1997, 2006, 2011; Robie, 2019; Robie \& Marbrook, 2020 for an indication in the Australasian context).

Fifthly, there are the profound intellectual and professional consequences of the establishment of the new 45 Indigenous Studies Division, including its three FoR codes for Aboriginal and Torres Strait Islander (450109), Māori (450713) and Pacific Peoples (451311) Literature, Journalism and Professional Writing respectively. Many Indigenous fields had previously been aggregated in the ANZSRC 2008 classification, but not given the status of Division on that occasion. The new status will precipitate major changes in funding, quality evaluation, research outcomes and coursework curriculum for both Indigenous and nonIndigenous Journalism. It is not for me to initiate that discussion, but simply to emphasise that it is upon us and is important. There is a literature on decolonising methodologies (e.g. Smith 2012; Archibald et al., 2019) that those journalism academics not familiar with it would do well to engage with, in anticipation of the changes poised to sweep through the field. More broadly, we can note that social, economic and political life in Australasia and the Pacific is still profoundly structured by colonial and neo-colonial relations; Oceanian countries are at the forefront of contemporary ecological crises; and that, bordering East Asia and the Americas, Oceania including Australasia is centre stage in the big geopolitical contests of the 21st century. Journalism in the 45 Division of Indigenous Studies may roar into huge significance internationally in these looming crises.

In conclusion, it is worth noting the longterm leadership role this journal has played, under the founding editor and director of the Pacific Media Centre at AUT, Professor David Robie, working with production designer Del Abcede. Robie and Pacific Journalism Review have long been a champion of the role of university-based journalism that the ANZSRC has recognised and mandated in its 2020 classification (eg Robie, 2015). Its prominent emphasis on Māori and Pasifika journalism, not just in terms of scholarly production but also through supporting journalists in the thick of professional, political and economic challenges, has been exemplary of the efforts that others will now need to emulate and develop. Likewise, the establishment of the Frontline section featuring and analysing journalism as research under the foundation leadership of Professor Wendy Bacon from the University of Technology, Sydney (UTS), another leading institution in the development of journalism as research, was a trailblazing innovation. 
In this tradition, a group of colleagues associated with Pacific Journalism Review propose to conduct an invited seminar in the first half of 2021 addressing the challenges and opportunities that flow from the ANZSRC 2020 classification. Hopefully in these COVID-19 times it will be a face-to-face and not a virtual seminar. The plan is for a selected collection of contributions to be refined and published as a book. Everyone interested in contributing to this project is welcome to contact the author at the email below.

Finally, it is worth re-iterating that right from 1993 when the ABS first issued its research classification including journalism, and notably from 2008 when the ANZSRC stipulated methodology as the sole criterion for inclusion and classification, Australasian journalism has been served with an invitation to world leadership in the role of journalism within universities. The ANZSRC 2020 classification reiterates that the invitation is still open, and indeed that it is shaping up as a pressing demand. Let us collectively rise to the occasion.

\section{References}

ABS (1993). Australian Standard Research Classification 1993. Retrieved from https:// www.abs.gov.au/ausstats/abs@.nsf/66f306f503e529a5ca25697e0017661f/37AFA60 27989B5A1CA25697E0018FDEB accessed 15 October 2020

ABS (1998). Australian Standard Research Classification 1998. Retrieved from https:// www.abs.gov.au/ausstats/abs@.nsf/0/2D3B6B2B68A6834FCA25697E0018FB2D? opendocument accessed 15 October 2020

ABS and Statistics New Zealand Tatauranga Aotearoa (2008). ANZSRC 2008. Retrieved October 15, 2020, from https://www.abs.gov.au/AUSSTATS/abs@.nsf/Lookup/129 7.0Main+Features 12008

ABS et al. (2020). Outcomes Paper ANZSRC Review 2019. Retrieved October 15, from https://www.mbie.govt.nz/dmsdocument/11518-outcomes-paper-australian-and-newzealand-standard-research-classification-review-2019

Archibald, J. et al. (Eds) 2019: Decolonising research: Indigenous storytelling as methodology. London, UK, Zed Books.

Bacon, W. (1997). Shifting notions of the public in journalism. Culture and Policy, $8(2), 65-91$.

Bacon, W. (2006). Journalism as research. Australian Journalism Review, 28(2) 147-157.

Bacon, W. (2011). Investigative journalism in the academy — possibilities for storytelling across time and space. Pacific Journalism Review : Te Koakoa, 17(1), 45-66. https:// doi.org/10.24135/pjr.v17il.371

Bacon, W. (2012). FRONTLINE: An innovative direction in academic journalism. Pacific Journalism Review : Te Koakoa, 18(2), 153-165. https://doi.org/10.24135/ pjr.v18i2.270

Birnbauer, W. (2019). The rise of non-profit investigative journalism in the United States. New York, NY. Routledge

Carey, J. (1997). The dark continent of American journalism. In E. Minson \& C. Warren (Eds)., James Carey: A critical reader. Minneapolis, MN: University of Minnesota Press.

Hartley, J. (1996). Popular reality. London, UK: Arnold. 
Nash, C. (2013). FRONTLINE: Journalism as a research discipline. Pacific Journalism Review: Te Koakoa, 19(2), 123-135. https://doi.org/10.24135/pjr.v19i2.221.

Nash, C. (2014). Research degrees in journalism: What is an exegesis?. Pacific Journalism Review: Te Koakoa, 20(1), 76-98. https://doi.org/10.24135/pjr.v20i1.188

Nash, C. (2016). What is journalism? The art and politics of a rupture. London, UK: Palgrave Macmillan.

Nash, C. (2017). Journalism: the question is ... Australian Journalism Review, 39(10), 25-29.

Robie, D. (2015). Advocating journalism practice-as-research: A case for recognition in the New Zealand PBRF context, Asia Pacific Media Educator, 25(1), 62-73. DOI $10.1177 / 1326365 X 15575591$

Robie, D. (2019). Karoronga, kele'a, talanoa, tapoetethakot and va: expanding millennial notions of a 'Pacific way' journalism education and media research culture. Media Asia, 46,(1-2), 1-17. DOI: 10.1080/01296612.2019.1601409

Robie, D. \& Marbrook, J. (2020).Bearing witness: A Pacific climate crisis documentary and journalism development project. Asia Pacific Media Educator, 30(10), 1-15. $10.1177 / 1326365 \times 20945417$

Smith, L. T. (2012). Decolonising methodologies: Research and indigenous peoples. London, UK: Zed Books.

Tuchman, G. (1978). Making news: A study in the construction of reality. New York, NY: Basic Books.

Windschuttle, K., Breen, M., \& Bacon, W. (1998). Letters and responses. Media International Australia (incorporating Culture and Policy), 86, pp. 135-142.

Dr Chris Nash was foundation Professor of Journalism at Monash University in Melbourne, Australia, and is on the editorial board of Pacific Journalism Review as an independent researcher. His book What is Journalism? The Art and Politics of a Rupture was published by Palgrave Macmillan in 2016.

chris@chrisnash.com.au 